\title{
Study of Blood Glucose and Serum Calcium Level in Small For Gestational Age Babies
}

\author{
Mazumder $\mathrm{MW}^{1}$, Begum $\mathrm{N}^{2}$, Mannan $\mathrm{MA}^{3}$
}

\begin{abstract}
Background: Incidence of hypoglycemia in small for gestational age (SGA) babies is high. Therefore small for gestational age babies need close biochemical monitoring of blood glucose for early diagnosis and immediate management of hypoglycemia to prevent future neurodevelopmental outcome. Objectives: The study was designed to measure blood glucose and serum calcium level in new born babies with SGA and to compare with normal new born babies. Methodology: This case control study was done in Neonatology Department of BSM Medical University, Dhaka from 01 July to 31 December 2006. Low birth weight newborn babies with birth weight below 10th centile for gestational age were considered as SGA babies whereas babies with gestational age more than 37 completed weeks and weight more than 2500 gm were considered as control group. Results: Thirty two cases and equal number of controls were studied. Among 32 babies with SGA, hypoglycemia was found in $46.9 \%$ of cases and $3.1 \%$ cases in control group which was statistically significant $(\mathrm{P}<.05)$. Incidence of hypoglycemia was more during $0-12$ hours $(57.9 \%)$. Hypocalcaemia developed in $9.4 \%$ and $6.3 \%$ of SGA and control group respectively and difference was not statistically significant. Conclusion: Hypoglycemia was significantly more in small for gestational babies specially during $0-12 \mathrm{hrs}$ of post natal life,
\end{abstract}

Key words: Blood glucose, serum calcium, small for gestational age (SGA) babies, LBW, IUGR

\section{Introduction}

Intrauterine growth and its aberrations are major concerns of modern obstetrics because birth weight is the strongest known indicator of perinatal mortality ${ }^{1}$. Birth weight depends on gestational age and foetal growth. Low birth weight (LBW) is defined as newborn with birth weight less than $2500 \mathrm{gm}$. Low birth weight infants thus may be classified as belonging to one of the following three groups like preterm (less than 37 completed weeks) appropriate for gestational age (Preterm AGA), preterm growth retarded/small for gestational age (preterm IUGR/SGA) and term (37 completed weeks) growth retarded (term IUGR/SGA) ${ }^{1}$.

The importance of analyzing birth weight as a function of gestational age is confirmed by the fact that this relationship has a direct effect on perinatal mortality \& morbidity. It was shown that within fixed gestational age strata, perinatal mortality is related inversely to birth weight ${ }^{2}$. Increase perinatal mortality associated with growth retardation is correlated with increase in both foetal and neonatal mortality rates. The morbidity associated with intrauterine growth retardation (IUGR) is also significant. The incidence of neurodevelopmental problem in both pre-term \& term growth retarded infants is significantly increased ${ }^{3}$. It has long been known that small for gestational age (SGA/IUGR) infants are less able to achieve the metabolic adaptation required at birth and thus are at risk of hypoglycaemia ${ }^{4}$. The incidence of hypocalcaemia in prematurely born infant is extremely high. In one study $50 \%$ of premature infants had serum calcium level below $8 \mathrm{mg} / 100 \mathrm{ml}$ of blood ${ }^{5}$. In other study $26 \%$ to $30 \%$ of low birth weight infants had serum calcium level $7 \mathrm{mg} / 100 \mathrm{ml}$ of blood which is defined as hypocalcaemia. The infants at greatest risk are low birth weight infants especially with intrauterine growth retardation, infants of diabetic mothers, infants who have been subjected to prolonged difficult deliveries ${ }^{6}$. Another study showed that neonatal hypocalcaemia was not associated with infants who were small for gestational age nor with neonatal hypoglycemia ${ }^{7}$. In addition the lack of correlation between neonatal hypocalcaemia and factors commonly associated with intrauterine growth retardation suggests that there is no defect in the intrauterine transfer,

1. Dr. Md. Wahiduzzaman Mazumder, Junior Consultant (Paediatrics), Chunarughat Health Complex, Hobiganj, Sylhet

2. Dr. Nazma Begum, Assistant Professor, Department of Paediatrics, Shaheed Suhrawardy Medical College and Hospital, Dhaka

3. Dr. M.A. Mannan, Associate Professor, Department of Neonatology, Bangabandhu Sheikh Mujib Medical University, Dhaka

\section{Correspondence :}

Dr. Nazma Begum, Assistant Professor, Department of Paediatrics, Shaheed Suhrawardy Medical College \& Hospital, Dhaka, Bangladesh Email: nazmabegum29@ymail.com; Cell no.: +8801819242374 
metabolism and assimilation of calcium from mother to foetus in IUGR babies ${ }^{8}$.

Low birth weight (LBW) is one of the major neonatal health problem in developing countries. About $22 \%$ of all new born in Bangladesh have LBW and of them major part is due to intrauterine growth retardation (IUGR). The newborn babies with SGA suffer from various metabolic problem like metabolic acidosis, obvious hypoglycemia, hypocalcaemia ${ }^{9}$. Hypoglycaemia may develop symptoms like apnoea, Jitteriness \& convulsions and have serious neurodevelopmental consequences ${ }^{9}$. Hypocalcaemia may develop symptoms like twitching of one or more extremities, highpitched cry, hypotonia \& convulsion ${ }^{10}$. Therefore LBW newborn babies who are small for gestational age needs close biochemical monitoring including blood glucose \& serum calcium level. Therefore the study was carried out to measure the level of blood glucose and serum calcium level of newborn babies with SGA and to compare with that of normal newborn babies who are not LBW nor preterm.

\section{Methodology}

This case control study was done in Department of Neonatology at BSMMU, Dhaka from 1st July to 31st December 2006. After admission all low birth weight (LBW) babies $(<2500 \mathrm{gm})$ were assessed. LBW newborn babies with birth weight below 10th centile for gestational age were declared as IUGR/SGA. Gestational age was assessed by maternal LMP and by New Ballard scoring. Thirty two (32) SGA newborn up to $24 \mathrm{hrs}$ of postnatal age excluding infant of diabetic mothers, new born babies with moderate to severe perinatal asphyxia, congenital anomalies and equal number of control (gestational age $>37$ completed weeks, wt $>2500 \mathrm{gm}$ ) were studied. According to the age of sample collection babies were grouped in group A (0-12 hours) and Group B (13-24 hours). A 1-2 ml of peripheral venous blood was drawn and sample was sent immediately to the laboratory. Serum calcium was measured by colorimetric test manual method expressed in $\mathrm{mg} / \mathrm{dl}$. Blood glucose was measured by auto analyzer (glucose oxidase method) expressed in $\mathrm{mmol} / \mathrm{L}$. Blood glucose level $<2.2$ $\mathrm{mmol} / \mathrm{L}(<40 \mathrm{mg} / \mathrm{dl})$ and serum calcium level $<7 \mathrm{mg} / \mathrm{dl}$ considered as hypoglycemia and hypocalcaemia respectively. Data were analyzed by computer, using SPSS17. Chi-square test was performed to see the association. $\mathrm{P}$ value less than 0.05 was considered as significant.

\section{Results}

The study showed that among 32 cases of newborn babies with SGA, 15(46.9\%) cases had blood glucose level less than $2.2 \mathrm{mmol} / \mathrm{L}(40 \mathrm{mg} / \mathrm{dl})$ considered as hypoglycemia and in the control group the hypoglycemia was found in $1(3.1 \%)$ newborn. Among cases $15(47 \%)$ had hypoglycemia and $17(53 \%)$ were normoglycemic. The comparative study of hypoglycemia between cases and controls showed high statistical significance $(\mathrm{p}=0.008)$ (table 1$)$.
Table 1: Comparison of Blood glucose level between study group

\begin{tabular}{lccc}
\hline $\begin{array}{l}\text { Study } \\
\text { Group }\end{array}$ & Hypoglycemic & Normoglycemic & Total \\
\hline Cases & $15(46.9)$ & $17(53.1)$ & $32(100.0)$ \\
Control & $1(3.1 .0)$ & $31(96.9)$ & $32(100.0)$ \\
Total & $\mathbf{1 6 ( 2 5 . 0 )}$ & $\mathbf{4 8}(\mathbf{7 5 . 0})$ & $\mathbf{6 4}(\mathbf{1 0 0 . 0})$ \\
\hline
\end{tabular}

* Chisquare test has been done corrected by Fishers' Exact test to measure the association.

${ }^{*} \mathrm{p}=0.008$ (statistically significant)

*Parenthesis indicates percentage.

Hypoglycemia was more in Group A during 0-12 hrs (57.9\%) than Group B during 13-24 hrs (42.1\%) of postnatal age but difference was not statistically significant (Figure I).

Figure I: Hypoglycemia according to post natal age (in hours)

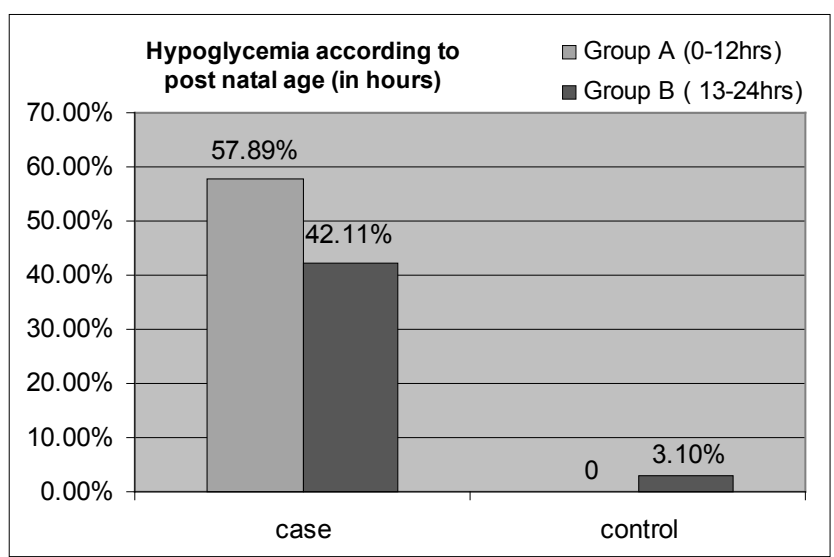

Among 32 cases of SGA babies $3(9.4 \%)$ cases had hypocalcaemia whereas hypocalcaemia was found in $2(6.2 \%)$ newborn babies in control group. Among cases 3 $(9.4 \%)$ had hypocalcaemia and 29(90.6\%) were normocalcaemic. The comparative study of hypocalcaemia between cases and controls showed no statistical significance $(\mathrm{P}=0.12)$ (Table 2$)$.

Table 2: Comparison of Blood glucose level between study group

\begin{tabular}{lccc}
\hline $\begin{array}{l}\text { Study } \\
\text { Group }\end{array}$ & Hypocalcaemia & Normocalcaemia & Total \\
\hline Cases & $3(9.4)$ & $29(90.6)$ & $32(100.0 \%)$ \\
Control & $2(6.3)$ & $30(93.8)$ & $32(100.0 \%)$ \\
Total & $\mathbf{5 ( 7 . 8 )}$ & $\mathbf{5 9}(\mathbf{9 2 . 2})$ & $\mathbf{6 4}(\mathbf{1 0 0 . 0})$ \\
\hline
\end{tabular}

*Chisquare test has been done corrected by Fishers' Exact test to measure the association.

$* \mathrm{p}=0.12$ (statistically not significant)

*Parenthesis indicates percentage.

\section{Discussion}

Sixty four babies were studied to determine blood glucose level and serum calcium level, among them 32 were SGA babies and 32 were control. Mean gestational age of cases 
$(n=32)$ were $36.34 \pm 2.34$ weeks and mean birth weight was $1646.88 \pm 434.21 \mathrm{gm}$. In the control group mean gestational age was $38.88 \pm 1.26$ weeks and birth weight was $3067.19 \pm$ $300.97 \mathrm{gm}$. Among the SGA babies $(\mathrm{n}=32)$ hypoglycemia was present $46.9 \%$ whereas $3.1 \%$ in control group. Similar studies have shown that the incidence of hypoglycemia in SGA babies was 4 to $36 \%{ }^{12,13}$. Similar observation had been made by Ketringham et $\mathrm{al}^{14}$ and Singhi et $\mathrm{al}^{15}$.

The variability of the incidence could be partly due to different policies of feeding and different degrees of neonatal sickness. Another important cause of the variability of incidence could be due to the fact that many of the mothers of the SGA babies in this study received intravenous glucose infusion during delivery. After complete delivery the high insulin milieu may aggravate already compromised glycogen stores in SGA babies.

The present study showed that hypoglycaemia was more (57.89\%) during $0-12$ hours than in $13-24$ hours $(30.76 \%)$ of post natal age. This may be partly explained by metabolic adjustment that occurs in early hrs after birth. The present study also showed that $9(50 \%)$ out of 18 cases of term SGA babies had blood glucose level less than $2.2 \mathrm{mmol} / \mathrm{L}$, which may be explained by their larger ratio of the glucose consuming brain to the small liver.

Among the control group 1(3.1\%) had blood glucose level $<2.2 \mathrm{~m} \mathrm{~mol} / \mathrm{L}$ (hypoglycaemia) which may be due to delayed initiation and lack of proper feeding in normal term babies and some time in sick babies with minor illness. Regarding serum calcium level, $3(9.4 \%)$ of study group had hypocalcaemia, in contrast to the control group where $2(6.3 \%)$ had serum calcium level below $7 \mathrm{mg} / \mathrm{dl}$. Similar results were found by Reginald et $\mathrm{al}^{16}$. Among the control group 2(6.3\%) babies had serum calcium level below $7 \mathrm{mg} / \mathrm{dl}$, which may be explained by associated mild perinatal asphyxia, suspected sepsis, or other causes.

\section{Conclusion}

In new born babies with SGA, incidence of hypoglycemia was significantly more, specially during $0-12 \mathrm{hrs}$ of post natal life, and hypocalcaemia though was not significantly more in SGA babies during early hours of life, both needs close clinical evaluation \& biochemical monitoring for early identification and proper management. Hypoglycemia should be treated promptly with early enteral or intravenous nutrition that may prevent adverse neuro-developmental outcome.

\section{References}

1. Raphel N, Pollack Y. Intrauterine growth retardation: Definition, classification and etiology. Clinical Obs Gynecology, 1992; 35:1-3

2. Williams RI, Creasy RK, Tashiru MS. Foetal growth \& Perinatal Viability in California. Obst. Gynecol 1990; 59: 624-27

3. Allen MC. Developmental out come and follow up of the small for gestational age infants. Perinatal 1994;8:102-105

4. Neligen GA, Robson E, Watson J. Hypoglycemia in the newborn. A Sequelae of Intrauterine Malnutrition. Lancet 1983;1:1282-89

5. Lubchenco LO, Bard H. Incidence of hypoglycemia in newborn infants classified by birth weight \& gestational age. Pediatrics 1971; 47:831-8.

6. Tsang RC. Neonatal hypocalcaemia in low birth weight infants, Pediatrics 1970;45:773

7. Attirkawi K, Rozycki HJ. Hypocalcaemia is common in the first 48 hour of life in ELBW infants. J Perinat Med 2008; 36(4): 348-53

8. Wigglesworth J.C. Foetal growth retardation. Brit Med Bull, $1985 ; 22: 13-17$

9. PD Gluckman. Metabolic consequence of intrauterine growth retardation. Acta paediatr suppl, $1996 ; 417: 8-13$

10. Fitzgeradd T.B. and Clift A.D. The foetal loss in pragnency Toxaemia. Lancet, 1985; 1: 283-87

11. Lucas A, Morley R, Cole TJ. Adverse- neurodevelopmental outcome of moderate neonatal Hypoglycemia. BMJ, 1988; 19:1304-05

12. Lubchencho LO, Bald H. Incidence of hypoglycemia in new born infants classified by birth weigh and gestational age. Pediatrics. 1971; 47: 831-838

13. Deelu W, D Vries I. Hypoglycemia in small for date newborn infants. Pediatrics 1996;58:18-22

14. Ketteringham RC, Austin BR. Induced hyperglycemia at delivery. Am J Obstet Gynaecol 1939; 37:1000-1005

15. Singhi S, Sharma S, Gopalan S. Maternal glucose infusion and risk of hypoglycemia in term infants. MD thesis PGIMER, 1988, Chandigarh 16. Raginald C, Sang T, William OH. Neonatal Hypocalcaemia in low birth weight infants. Pediatrics 1970; 45:(5):77-81 